\title{
Functional Nanohybrid Materials from Photosynthetic Reaction Center Proteins
}

\author{
Kata Hajdu, ${ }^{1,2}$ Tibor Szabó, ${ }^{1,2}$ Abd Elaziz Sarrai, ${ }^{1,3}$ László Rinyu, ${ }^{2}$ and László Nagy ${ }^{1}$ \\ ${ }^{1}$ Department of Medical Physics and Informatics, University of Szeged, Szeged, Rerrich B. tér 1, 6721, Hungary \\ ${ }^{2}$ Isotope Climatology and Environmental Research Centre (ICER), Institute for Nuclear Research, Hungarian Academy of Sciences, \\ Debrecen, Bem tér 18/c, 4026, Hungary \\ ${ }^{3}$ Laboratory for Biomaterials and Transport Phenomena LBMPT, University Yahia Fares, 26000 Medea, Algeria
}

Correspondence should be addressed to Tibor Szabó; tiberatosz@gmail.com

Received 13 June 2017; Accepted 17 August 2017; Published 17 September 2017

Academic Editor: Leonardo Palmisano

Copyright (c) 2017 Kata Hajdu et al. This is an open access article distributed under the Creative Commons Attribution License, which permits unrestricted use, distribution, and reproduction in any medium, provided the original work is properly cited.

Application of technical developments in biology and vice versa or biological samples in technology led to the development of new types of functional, so-called "biohybrid" materials. These types of materials can be created at any level of the biological organization from molecules through tissues and organs to the individuals. Macromolecules and/or molecular complexes, membranes in biology, are inherently good representatives of nanosystems since they fall in the range usually called "nano." Nanohybrid materials provide the possibility to create functional bionanohybrid complexes which also led to new discipline called "nanobionics" in the literature and are considered as materials for the future. In this publication, the special characteristics of photosynthetic reaction center proteins, which are "nature's solar batteries," will be discussed in terms of their possible applications for creating functional molecular biohybrid materials.

\section{Introduction}

Light plays a central role in the evolution and sustaining the present state of life on Earth. The conversion of light energy into chemical energy is the most important driving force for the ecosystems. Most importantly, the energetic base of human civilization relies on fossil fuels, which are the energy deposits of photosynthetic organisms of the past million years [1]. Light-matter interactions are fundamental importance both from the point of view of basic science and practical applications (e.g., in optoelectronic systems designed for energy conversion, imaging devices, optical switches, and sensor technologies) [2-6]. There are various principles for light energy conversion both in living systems and in artificial molecular devices [7-12]. Light energy can be converted, for example, into (a) heat (photothermal processes; most typical example is the greenhouse effect or phenomenon used in solar panels which heat water); (b) the energy of charge pairs (photoelectric processes in energy-converting proteins or in CCD-imaging detectors, photocells); and (c) utilization of the free energy of chemical reactions (photography and photosensibilization reactions).

There are several reasons why mankind needs more and more efficient technologies in the near future [2-4]. (1) The exponential growth of the human population cannot be supplied with energy without technological developments. (2) The natural resources (minerals and fossil fuels) are not inexhaustible. (3) The new technologies should be environmental friendly, with as little poisonous and waste side products as possible. (4) The quality of life and the healthcare system also requires new, innovative technologies.

The new generation of practical applications requires optimization of several specific tasks in which nanotechnology offers unique solutions. One should optimize the size of the devices and sample quantities-aiming for single molecular operation and/or fast, reversible, and reproducible responses, also for online, real-time, sensitive, and selective detection [13-15]. Discovering new types of materials and technologies led to the birth of new phenomena and disciplines, like optoelectronics, (bio)photonics, nanotechnology, 


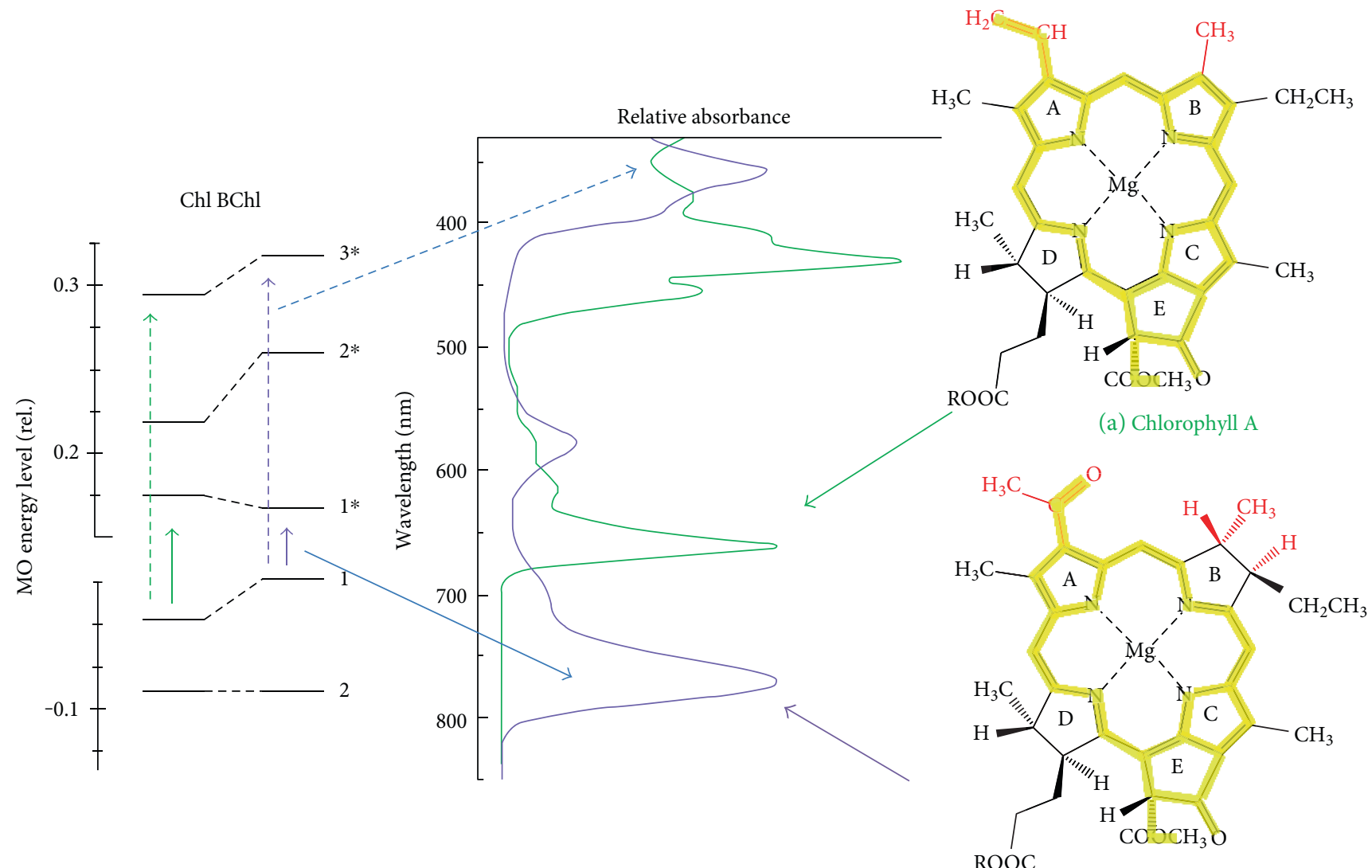

(b) Bacteriochlorophyll A

FIGURE 1: The connection between the molecular, energetic, and spectral characteristics of the chlorophyll and bacteriochlorophyll molecules. The molecular orbital (MO) levels of chlorophylls (Chl) and bacteriochlorophylls (BChl) (left). The $\mathrm{S}_{0} \rightarrow \mathrm{S}_{1}$ and $\mathrm{S}_{0} \rightarrow \mathrm{S}_{n}$ (Soret) transitions are indicated by solid and dotted lines, respectively. The absorption spectra of chlorophyll-a and bacteriochlorophyll-a corresponding to the $\mathrm{S}_{0} \rightarrow \mathrm{S}_{1}$ and $\mathrm{S}_{0} \rightarrow \mathrm{S}_{n}$ transitions as indicated by the characteristic lines (middle). The molecular structures of chlorophyll-a and bacteriochlorophyll-a molecules (right). The conjugated double bond systems are highlighted.

and nanobionics. Nanohybrid materials provide possibility to create functional bionanohybrid complexes which became a new discipline called "nanobionics" in the literature [16] and are considered as materials for the future in the literature $[3,4,17,18]$.

Photosynthetic reaction center (RC) complexes found in the membranes of living cells $[1,7,8]$ represent inherent examples of nanobionics, optoelectronics, and photonics. RCs, which are nature's solar batteries, fall in the range usually called "nano" (their size is about $10 \mathrm{~nm}$ [19-21], and their operation is also on the "nano" scale) using a single photon of light to power a single chain of intraprotein electron transfer event that leads to the separation of a single pair of electrical charges within the protein complex. The special biological functions and optoelectric/photonic properties of these molecular assemblies are determined by their molecular structures and structural and functional hierarchy of their constitutions [4].

1.1. The Characteristic Molecules of Photosynthesis Are the Chlorophylls. The most characteristic molecules of the photosynthetic energy conversion are the chlorin type compounds, the chlorophylls (in plants, algae, and cyanobacteria), and bacteriochlorophylls (in photosynthetic bacteria). The roles of these molecules in photosynthesis are warranted by the strong connection of their unique molecular structures with specific spectral and chemical characteristics which fundamentally determine their biological functions. Due to the organization of the delocalized conjugated molecular orbitals, these molecules have special, experimentally measurable redox (electron transfer) and spectral (light absorption and emission) characteristics $[22,23]$.

1.1.1. Spectral Characteristics. Thanks to the extended conjugation in the highest occupied molecular orbitals (HOMO), the wavelength range of these chlorin molecules usable for photosynthetic energy conversion falls in the range of the $\mathrm{red} /$ near infrared (e.g., $\mathrm{S}_{0} \rightarrow \mathrm{S}_{1}$ transition) and in the blue (the so-called Soret bands) of the absorption spectrum (Figure 1). Although the difference in the degree of the delocalization between the chlorophyll and bacteriochlorophyll pigments is small (note that the delocalization on the Bring is disrupted and the ethylene group is substituted by acetyl group on the A-ring in bacteriochlorophyll), this difference has great influence on chemical and biological functions. Note that the lower degree of delocalization in bacteriochlorophylls increases the energy level of HOMO (smaller stability of the valence electrons of the molecule) 
and decreases, in turn, that of the lowest unoccupied molecular orbital (LUMO).

Due to this difference in the delocalization, the energy difference between the HOMO and LUMO is larger in the chlorophyll which is reflected in the spectroscopically measurable $S_{0} \rightarrow S_{1}$ transition, corresponding to the light absorption at about $660 \mathrm{~nm}$ in organic solvents. This change corresponds to smaller energy of the $S_{0} \rightarrow S_{1}$ transition for bacteriochlorophyll-a and to a maximum absorption at $\lambda=760 \mathrm{~nm}$ in organic solvents.

1.1.2. Redox Properties. Chlorophylls are not only pigments (dyes with characteristic absorption bands in the visible range of the spectrum) but, in addition, they are capable of participating in oxidation/reduction reactions, that is, they are redox active compounds with specific redox midpotentials. The disruption in the degree of delocalization in the $\mathrm{HOMO}$, in the case of bacteriochlorophyll, is associated not only with the longer wavelength in the light absorption but also with more negative redox midpotential (compared to chlorophyll). The redox midpotential of the bacteriochlorophyll is $E_{\mathrm{m}} \approx 400 \mathrm{mV}$ (as compared to the standard hydrogen electrode (SHE)) in organic solvent. The larger HOMO-LUMO gap in chlorophyll is accompanied by smaller $\mathrm{e}^{-}$-donating (reducing) or larger $\mathrm{e}^{-}$-withdrawing (oxidizing) power in the case of chlorophyll $\left(E_{\mathrm{m}} \approx 500 \mathrm{mV}\right.$ compared to SHE). This small but fundamental difference in the structure and in the chemical nature of these compounds becomes more important when these pigments are assembled in biological structures and have played an essential role in the evolution of the present form of biosphere. Thanks to its larger oxidation power, chlorophyll-based organisms are capable of evolving oxygen by water splitting while those containing bacteriochlorophylls perform anoxygenic photosynthesis. Note that oxygenic photosynthesis has changed the surface of the globe: the atmosphere turned from reducing to oxidizing, and it has been keeping the present state of the biosphere for millions of years.

\subsection{Light Energy Is Converted into Chemical Potential in the Reaction Center Protein}

\subsubsection{The Energetic Requirement of Charge Separation} and Stabilization. Chlorophylls and bacteriochlorophylls, together with other chlorin and carotenoid pigments and with quinone molecules, are organized in special pigmentprotein complexes (light-harvesting antenna complexes and RC proteins) found in the photosynthetic membrane of cells for efficient photoelectric energy conversion [1]. The role of the light-harvesting antenna complexes is the efficient light absorption and the transferring of the absorbed energy to the RCs, which are the most efficient light energy converter systems in nature [24, 25].

Nature developed different types of RCs (photosystem I (PS I) and photosystem II (PS II) in plants, algae and cyanobacteria and type I and type II RCs in green and purple photosynthetic bacteria, resp.). All have similar molecular architecture: redox active cofactors (chlorin pigments and quinone molecules) are bound to the proteins. The basic

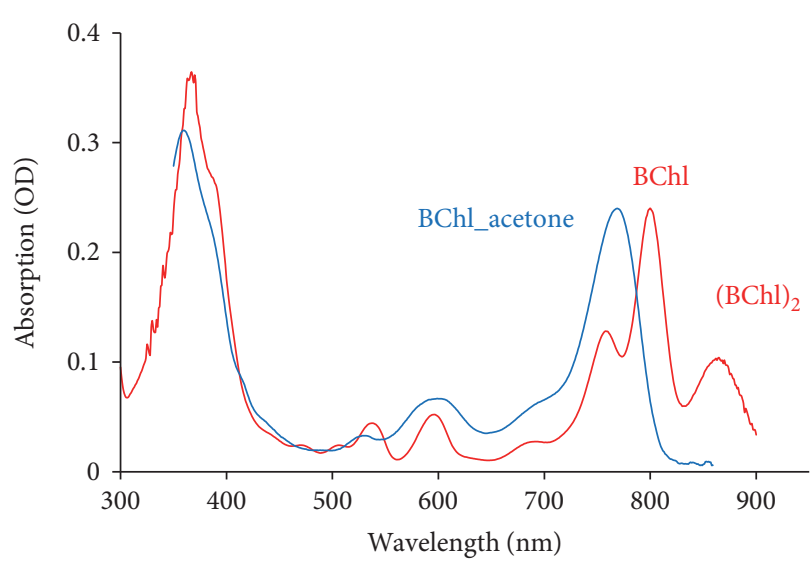

FIgURE 2: The absorption spectra of bacteriochlorophyll-a in organic solvent $\left(\lambda_{\max }=770 \mathrm{~nm}, \mathrm{ET}-\mathrm{OH}\right)$, bound to the RC in the form of monomer (called "accessory chlorophylls," $\lambda_{\max }=802 \mathrm{~nm}$ ) and in the form of dimer (called primary electron donor, $(\mathrm{BChl})_{2}$, $\left.\lambda_{\text {max }}=860 \mathrm{~nm}\right)$.

function of the RCs after excitation by light is the separation and stabilization of the light-activated charges accompanied by the rearrangement of charges and hydrogen-bonding interactions within and around it [26-35].

The spectral and redox properties of the cofactors are key factors in the functioning of the RCs. This pigment-protein complex is organized to carry out very efficient energy conversion. When chlorophylls are bound to the protein, the $\mathrm{S}_{0} \rightarrow \mathrm{S}_{1}$ transition is shifted to lower energy values and the energy of the created charge pair in the protein is adjusted to one of the absorbed photons. Figure 2 shows that the electric energy of the $S_{0} \rightarrow S_{1}$ transition of bacteriochlorophyll corresponds to about $770 \mathrm{~nm}$ in organic solvent. When BChl is bound to the RC in the form of monomer, the value of $770 \mathrm{~nm}$ is shifted to about $800 \mathrm{~nm}$ due to the interactions with amino acids. In the case of the BChl dimer, $(\mathrm{BChl})_{2}$-the special pair which is the primary electron donor of the RC protein (see the next paragraph) - this value is about $860 \mathrm{~nm}$.

The spectral change of the $\mathrm{BChl}$ accompanies with the $E_{\mathrm{m}}$ shifted moderately (from $400 \mathrm{mV}$ to $450 \mathrm{mV}$ in the ground state $\left.\mathrm{P}_{860}^{+} / \mathrm{P}_{860}\right)$ in the form of the special pair. This value is far too low with respect to the energetic requirement of water oxidation. Note that the midpotential of $\mathrm{H}_{2} \mathrm{O} / \mathrm{O}_{2}$ is $820 \mathrm{mV}$.

When the chlorophylls are bound to the photosynthetic reaction center protein, the $E_{\mathrm{m}}$ is shifted to a more positive (oxidizing) value, from $500 \mathrm{mV}$ to $1200 \mathrm{mV}$. This value is the midpoint potential of the primary photochemistry process (the redox couple of the ground state $\mathrm{P}_{680}^{+} / \mathrm{P}_{680}$ ) of photosystem two (PS II) in plants, algae, and cyanobacteria. It is important to note here that this is the most oxidizing redox system in living cells, which thus fulfills the energetic requirements of water splitting.

After light absorption, the midpoint potential of the chlorophyll $\left(\mathrm{P}_{680}^{+} / \mathrm{P}^{*}{ }_{680}\right)$ redox couple and that of the bacteriochlorophyll $\left(\mathrm{P}_{860}^{+} / \mathrm{P}^{*}{ }_{860}\right)$ primary donors are shifted to a considerably more negative value, $E_{\mathrm{m}}=-640 \mathrm{mV}$ and $E_{\mathrm{m}}=$ $-930 \mathrm{mV}$, respectively. Consequently, the difference in the $E_{\mathrm{m}}$ values between the excited and ground state couples of 


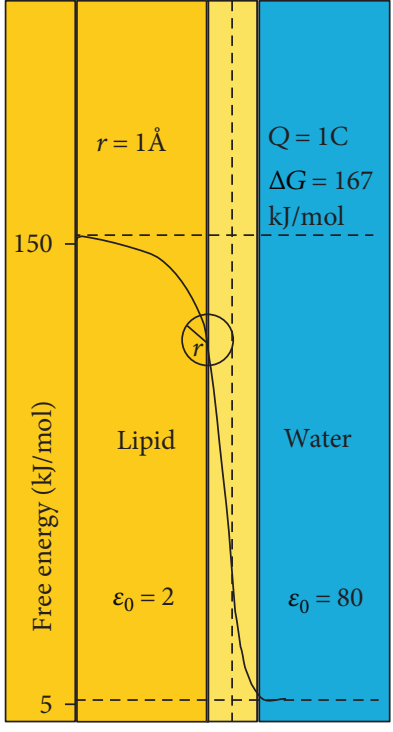

(a)

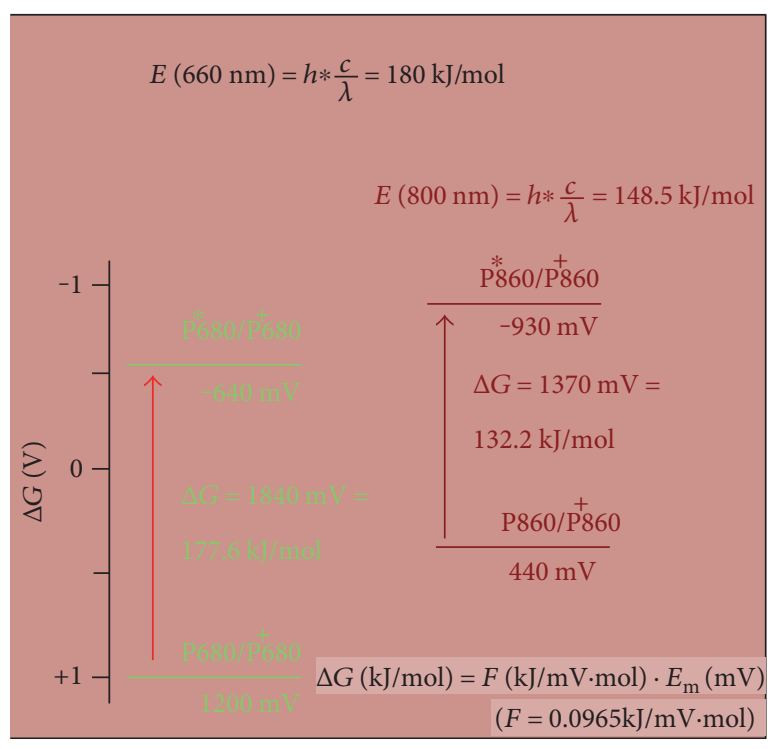

(b)

FIGURE 3: Comparison of the Coulomb free energy for transition of single charge from water to lipid phase of the membrane (a) with the redox free energy of transition from ground state to excited state primary donors of photosystem II $\left(\mathrm{P}_{680}\right)$ and bacterial RCs $\left(\mathrm{P}_{860}\right)(\mathrm{b})$. For comparison, the free energy of 1 mole photon with the wavelength of $660 \mathrm{~nm}$ and $800 \mathrm{~nm}$ (wavelengths that are characteristic to chlorophyll and bacteriochlorophyll absorption, resp.) is also indicated. See explanation in the text.

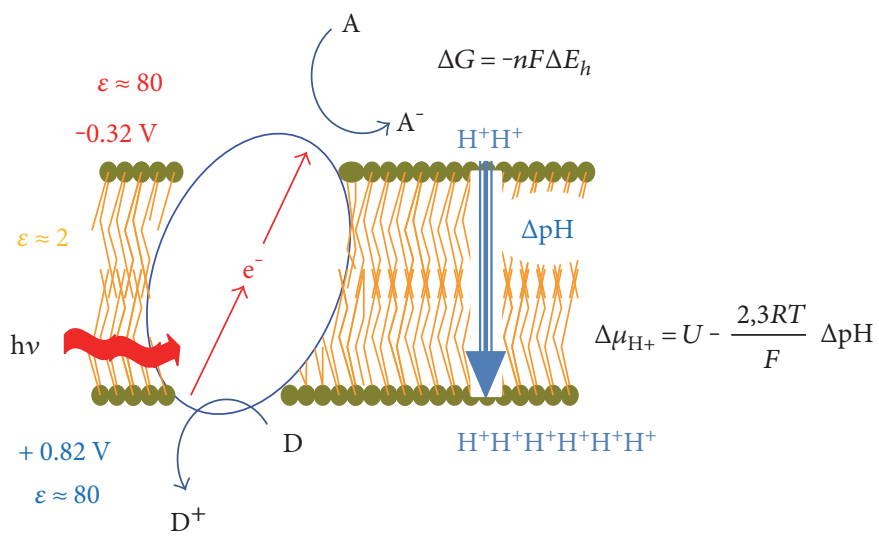

Figure 4: Schematic representation of connection of free energy of light $(\mathrm{h} v)$ to redox free energy of secondary donor $\left(\mathrm{D}^{+} / \mathrm{D}\right)$ and acceptor $\left(\mathrm{A} / \mathrm{A}^{-}\right)$redox systems and to the proton motive force (pmf, $\left.\Delta \mu_{\mathrm{H}}\right)$ driven by continuous turnover of the RC protein in the membrane. See explanation in the text.

the primary donors is $\Delta E_{\mathrm{m}}=1840 \mathrm{mV}$ (corresponding to a free energy difference, $\Delta G=177.6 \mathrm{~kJ} / \mathrm{mol}$ ) and $\Delta E_{\mathrm{m}}=1370 \mathrm{mV}$ $(\Delta G=132.2 \mathrm{~kJ} / \mathrm{mol})$ for chlorophyll-a and bacteriochlorophyll-a, respectively. These values coincide with the $S_{0} \rightarrow S_{1}$ transitions in the red $(\lambda=660 \mathrm{~nm}(\Delta G=180 \mathrm{~kJ} / \mathrm{mol})$ and near infrared $\lambda=860 \mathrm{~nm}(\Delta G=138 \mathrm{~kJ} / \mathrm{mol}))$ for chlorophyll-a and bacteriochlorophyll-a, respectively [4].

Note that upon charge separation, an electron is transferred across the photosynthetic membrane, separating thereby very oxidative and reductive environments on the two sides of the membrane. Assuming a very apolar environment inside the membrane $\left(\varepsilon_{0} \approx 2\right)$ and polar in the aqueous phases $\left(\varepsilon_{0} \approx 80\right)$, the energetic requirement of the electron transition from one phase to the other one can be estimated. The main interactions are determined by the Nernst equations (1) and (2) and by the solvatation potential (3). According to the Nernst equation, the Gibbs free energy $\left(G_{x}\right)$ is as follows:

$$
G_{x}=G_{x}^{0}+n_{x} R T \ln c_{x}+n_{x} Z F \Psi_{x} .
$$

Here, $n_{x}$ is the mol of ion, $\Psi_{x}$ is the electric potential, $c$ is the concentration, and $Z$ is the charge of the ion in the given space of $n_{x}$ mol ion in $x$ place, where the electric potential is $\Psi_{x} . R$ and $F$ are the universal gas constant and the Faraday constant, respectively. $T$ is the absolute temperature. $G_{x}{ }^{0}$ is the normal potential (when the concentration of the ion is 


$$
\begin{aligned}
& \text { (1) } \Delta G_{\text {photon }}=\mathrm{h} v \\
& \text { (2) } \Delta G_{E h}=n F \Delta E_{h} \\
& \text { (3) } \Delta \mu_{\mathrm{H}+}=U-\frac{2.3 R T}{F} \Delta \mathrm{pH} \\
& \text { (4) } \Delta G_{\mathrm{Pi}}^{0}=\Delta \Sigma \mu_{i}^{0} N_{i}^{0}=-R T \ln K
\end{aligned}
$$

Scheme 1: Steps of the free energy conversion in the reaction scheme of photosynthesis. Energy of photon (1) is converted to redox potential (2) of the cofactors within the RC and between the protein components of the electron transport chain. Redox free energy is coupled to proton motive force (3) across the membrane, which is coupled to phosphorylation potential (4) indicated by the solid lines.

$1 \mathrm{~mol}$ ). The free energy difference, $\Delta G_{r}$, for the transition of the ion from place "a" to "b" is as follows:

$$
\Delta G_{r}=R T \ln \left(\frac{c_{b}}{c_{a}}\right)+Z F\left(\Psi_{b}-\Psi_{a}\right)
$$

In addition, the solvatation potential (Born energy) should also be taken into account:

$$
\Delta G_{r}=-\left(\frac{Z^{2} e F}{8 \pi \varepsilon_{0} r}\right)\left(1-\frac{1}{\varepsilon_{r}}\right)
$$

$\varepsilon_{r}$ is the relative dielectric constant of the environment of the ion having radius $r$. By combining the two equations (2) and (3), one can calculate

$$
\Delta G_{r}=R T \ln \left(\frac{c_{b}}{c_{a}}\right)+Z F\left(\Psi_{b}-\Psi_{a}\right)+\left(\frac{Z^{2} e F}{8 \pi \varepsilon_{0} r}\right)\left(\frac{1}{\varepsilon_{b}}-\frac{1}{\varepsilon_{a}}\right)
$$

For an ion, if $r=1 \AA$ and $q=1 \mathrm{C}$, one will get $\Delta G=167 \mathrm{~kJ} /$ mol energy when transferred from water to lipid membrane.

It is interesting to note that this value is commensurate with the energy of one mol photon in the red part of the visible range and with the free energy difference between the excited and ground states of the primary electron donors of photosynthetic reaction centers in plants and bacteria (Figure 3). The photosynthetic reaction center (RC) protein is a specific molecular device, which provides a specific mechanism to transfer an electron across the membrane. RC converts photon energy $(h v)$ into the free energy of the redox couple of donor/acceptor system $\left(\Delta G_{\mathrm{Eh}}, \mathrm{D}^{+} /\right.$ $\mathrm{D} / / \mathrm{A} / \mathrm{A}^{-}$) separated by the membrane and connected to this protein complex which is the source of proton motive force (pmf, $\Delta \mu_{\mathrm{H}+}$ ) and of phosphate potential of phosphorylated metabolites $\left(\Delta G_{\sim \mathrm{Pi}}^{0}\right.$ like ATP, Figure 4 and Scheme 1$)$ $[36,37]$. The different types of Gibbs free energy forms are summarized in Scheme 1.

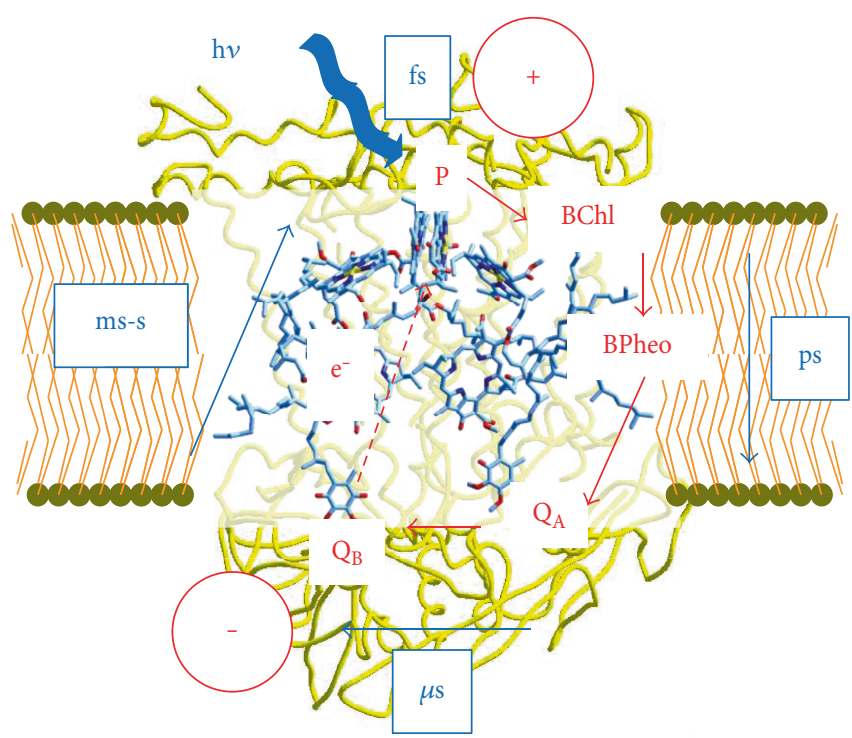

FIGURE 5: Schematic representation of the arrangement of RC cofactors and the charge stabilization routes in the photosynthetic membrane. Solid and dashed arrows indicate the forward charge separation and the backward charge recombination routes, respectively. P: primary electron donor; $\mathrm{BChl}$ : bacteriochlorophyll; BPheo: bacteriopheophytin; $\mathrm{Q}_{\mathrm{A}}$ : primary quinone type electron acceptor; $\mathrm{Q}_{\mathrm{B}}$ : secondary quinone type electron acceptor. The time intervals in which the appropriate processes occur are also indicated in blue boxes.

1.2.2. Vectorial Electron Transport in the Reaction Centers. In type II reaction center proteins, the absorption of light initiates a vectorial $\mathrm{e}^{-}$-transport, that is, an electron is transferred from the specially organized chlorophyll or bacteriochlorophyll type primary $\mathrm{e}^{-}$-donor $(\mathrm{P})$ to quinone $(\mathrm{Q})$ acceptor molecules through redox active cofactor pigments (for review, see, e.g., [1, 38-40]). Finally, a pair of “+” and “-” centers $\left(\mathrm{P}^{+} \mathrm{Q}_{\mathrm{A}}^{-}\right.$, or $\mathrm{P}^{+} \mathrm{Q}_{\mathrm{B}}^{-}$, here $\mathrm{Q}_{\mathrm{A}}^{-}$and $\mathrm{Q}_{\mathrm{B}}^{-}$are the reduced quinone type primary and secondary $\mathrm{e}^{-}$-acceptors) is created resulting in stabilization of the created charge pair (Figure 5).

If the protein is purified from its native environment, the secondary electron donor and/or acceptors are absent, so that the RC is reset only by the recombination of the "+" $/$ "-" charge pairs. However, in vivo (or mimicking the in vivo conditions in artificial systems) the oxidized primary donor is reduced by an external electron donor and the excited electron is driven in the direction of the metabolic pathways of the cells, assuring the conditions for repeated turnover of the RCs.

The time constant of the redox cycle of the RC is determined by the species of the redox cofactors bound to it and the types of interactions with the RC. By changing the appropriate redox components, wide range of $\mathrm{RC}$ turnover rates can be engineered (from $10^{12}$ to $10^{-1} \mathrm{~s}^{-1}$ ). Any of the redox cofactor components of the RC can be artificially modified (washed out from the RC and chemically or genetically changed, see, e.g., [41-43]). In general, proteins can be designed and constructed at will, in a broad range, to generate redox processes with different turnover times and conditions. 


\section{Photosynthetic Systems in Bionanotechnology}

Macromolecules and/or molecular complexes, membranes in biology, are inherently good representatives of nanosystems, since, as pointed out above, they fall in the range usually called "nano." It is interesting to emphasize that although the size of the reaction center protein falls in this range (ca. $10 \mathrm{~nm}$ [19-21]) and a single charge pair is created upon absorption of a single photon, this protein has dramatically changed the surface of the globe in geological time and it is called "the nature's solar power stations." Thanks to the strong connection of the molecular structure to spectral and chemical characteristics (see above), RC has unique physical-chemical properties, which are largely retained in biohybrid systems motivating a big challenge to use it in technical applications $[2,3]$.

(a) Characteristic light absorption of the electromagnetic spectrum in the near infrared range (700-1000 nm). This spectral range is just at the border of the visible light. It is already not visible but can be handled conveniently by optical devices (e.g., by detectors). The characteristic peaks in the near infrared are still present when RC is bound to nanostructures. Small shift in the peak position and change in the half width of the primary donor absorption are reported when RC is bound to multiwalled carbon nanotubes [44].

(b) After excitation by light, there are processes occurring inside the protein with different lifetimes on a wide time scale. We can find processes from few femtoseconds of the excitation to the picoseconds of the charge separation or to seconds of the charge recombination. The RC protein can be either engineered by genetic manipulations of the cells or modified by chemical treatment of the purified protein. Hence, it is possible to generate redox processes in virtually any time interval that we are interested in. The lifetimes of the redox transients are accompanied by characteristic spectral changes. The characteristic kinetic components of the electron transport, which are present in detergent micelles, are also identified when the RC is bound to different nanostructures, like CNTs, ITO, and conducting polymer, although modified in some extent $[19,44,45]$.

(c) As stated above, every absorbed photon is capable of generating a charge pair in the reaction center. The charge pair is created in the ps timescale and the lifetime of the charge separated state ranges in the ns-s time scale; the quantum efficiency is almost $100 \%$. Note that when using an appropriate wavelength for the excitation, the energy yield of the charge separation is also close to $100 \%$. There is no man-made device up to now which is even close to this value. The difference between the forward and backward electron transport rates is about 10 orders of magnitude which assures almost $100 \%$ quantum yield of charge stabilization also in nanostructures. This high quantum yield is maintained in living organisms by the continuous turnover of the secondary donor and acceptor sides of the RC. One of the bottlenecks of the practical application is the efficient electron transfer capacity between the RC and the external redox active components, which is far from $100 \%$ in recent applications $[46,47]$.

(d) It is interesting to note that the created charge pair has a distance of ca. $6 \mathrm{~nm}$ inside the protein and creates approximately $1 \mathrm{~V}$ surface potential difference [48]. From this value, one can estimate about $1 \mathrm{~V} /$ $6 \mathrm{~nm}=1.6 \cdot 10^{8} \mathrm{~V} / \mathrm{m}$ electric field $[49,50]$. This value is commeasurable with the membrane potential created by the work of active membrane pumps. Although this electric field is extremely high, there are only special molecular structures (structural changes of voltage sensitive ion channels and electrochromic shifts in the absorption spectrum of carotenoids and bacteriopheophytin) which are sensitive to it [51-56]. The existence of this extremely high electric field offers special optoelectronic applications.

(e) The redox centers arisen inside the protein after excitation by light can interact with their environment (either in the donor or in the acceptor side). The created redox systems ideally can be made to work, offering numerous potential application. There are successful essays in nanosystems as well, for example, $\mathrm{RC}$ can be bound in carbon nanotubes, transition metal oxides, and porous silicon. In these systems, the electron-excited by light-is trapped in the redox system around the RC and, among other things, it can be a part of an electrical circuit segment. This redox system might be used to couple to external redox components and to drive electron transfer reactions [57, 58]. There is a large interest in substituting natural redox carriers (cytochrome and quinones) by inorganic carrier matrices, which are able to donate/accept electrons to/from the RC as secondary electron donors/acceptors. These functional redox active bionanohybrid materials are promising models for photoelectric energy conversion in either optoelectronic or photovoltaic devices (for reference see, e.g., [59-62], details are given in the forthcoming paragraphs).

(f) Cofactors which are not components of the electron transfer routes (electron transport inhibitors, like photosynthetic herbicides) can also bound to specific sites of the RC blocking herby the light-induced charge separation. The binding is effective and specific, so that the RC-based biohybrids can be used as active components of biosensor devices [63-66].

In addition to the obvious advantages, the main bottleneck of any application of biohybrid systems is their extreme sensitivity. After extracting the biological components from the natural environment, usually, they lose their original activity. However, there are indications that by binding them 


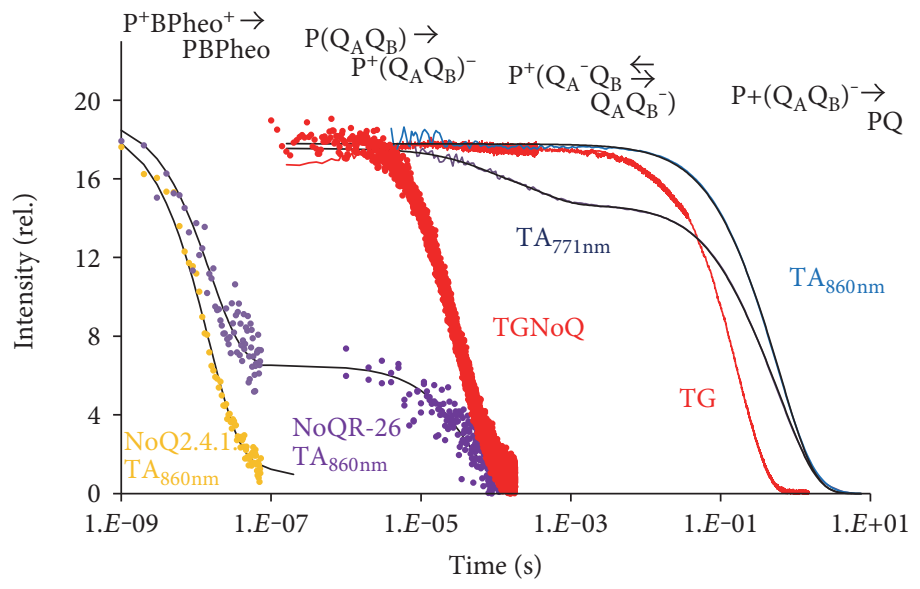

FIgURE 6: Representative examples of transient absorption and grating signal changes on a suspension of quinone-depleted (NoQ) RC and of a quinone-reconstituted RC; the RCs were purified from carotenoidless purple bacterium Rb. sphaeroides R-26. For comparison, the TA signal of quinone-depleted carotenoid-containing $\mathrm{Rb}$. sphaeroides 2.4.1. RC is also plotted. TA was measured at two wavelengths (771 and $860 \mathrm{~nm})$ as indicated and described in [43, 72]. TG was measured as described in [20]. Reaction schemes for the primary charge separation $\mathrm{PQ} \rightarrow \mathrm{P}^{+}\left(\mathrm{Q}_{\mathrm{A}} \mathrm{Q}_{\mathrm{B}}\right)^{-}$, interquinone electron transfer $\mathrm{P}^{+}\left(\mathrm{Q}_{\mathrm{A}}^{-} \mathrm{Q}_{\mathrm{B}} \leftrightarrows \mathrm{Q}_{\mathrm{A}} \mathrm{Q}^{-}\right)$, and the charge recombination $\mathrm{P}^{+} \mathrm{BPheo}{ }^{-} \rightarrow \mathrm{PBPheo}$ and $\mathrm{P}^{+}\left(\mathrm{Q}_{\mathrm{A}} \mathrm{Q}_{\mathrm{B}}\right)^{-} \rightarrow \mathrm{PQ}_{\mathrm{A}} \mathrm{Q}_{\mathrm{B}}$ are also indicated. $\mathrm{TA}$ and $\mathrm{TG}$ signals are normalized to the maximum values.

to nanostructures, their biological activity is partly retained. The hydrophobic character of the carbon nanotubes, or graphene, can mimic the membrane environment in vivo providing a larger stability for the RCs [19, 71, 80].

2.1. Optical Switches. The essential function of the RC in living systems is the separation and stabilization of charges in an extremely effective way. All the structural and functional (kinetic and energetic) conditions of the protein are optimized to fulfill these duties [4, 39]. Obviously, these unique characteristics offer special possibilities for application where fast response at specific wavelength is required. Based on the optical characteristics (in the light absorption and refractive index) during the photocycle, implications for ultrafast integrated optical data-processing technology were already demonstrated by using bacteriorhodopsin, which is another light energy-converting protein [67, 68].

Similar to the case of the bacteriorhodopsin, RC also accomplishes a photocycle-accompanying tunable lifetimes and wavelength ranges of absorption and refractive index changes from sub-ps to s time scales $[20,69]$ (Figure 6). It must be noted that the whole photocycle is under intensive discussion in the literature and outside the scope of the present publication. Figure 6 provides representative examples of changes in light-induced transient absorption and grating (this later is proportional with the square of the change in the refractive index) under different sample preparations $[20,69,70]$. It must be mentioned that in addition to the examples presented here, fine-tuning of lifetimes can be achieved from sub-ps to $s$ time scales by either genetic engineering or postmodification of the protein structure.

2.2. Intraprotein Charge Separation. In addition to the primary goal of the charge separation (which is creating and separating reducing and oxidizing species), there are accompanying features which might be interesting when practical applications are concerned. One of them is the transient of extremely high (ca. $10^{8} \mathrm{~V} / \mathrm{m}$, see above) electric field. The typical example of this phenomenon is the transient spectral perturbation of (electrochromic effect on) bacteriopheophytin (BPheo, which is one of the cofactors of the electron transport chain, Figure 5). The transient absorption occurs in the few tens to hundreds of $\mu$ s timescale, which is characteristic to the $\mathrm{Q}_{\mathrm{A}}^{-} \mathrm{Q}_{\mathrm{B}} \rightarrow \mathrm{Q}_{\mathrm{A}} \mathrm{Q}_{\mathrm{B}}^{-}$forward electron transfer (cf. the absorption transient $\mathrm{TA}_{771 \mathrm{~nm}}$ in Figure 6). Here, $\mathrm{BPheo}$ is functioning as an internal voltmeter for detecting the change in the electric field within the protein $[43,54,55]$.

In living organisms, potential difference across the membrane is created due to physiological processes with the substantial contribution of the RCs as well. The value of the electric field created by ca. $100 \mathrm{mV}$ membrane potential falls in the range which can be detected and investigated directly by electric measurements carried out on membrane fragments. Furthermore, the membrane potential which is created by the charge movements can be a source of thermodynamic "backpressure" on the charge transfer process [71].

There are experiments indicating that binding of RCs to conducting metal oxide (like ITO, $[45,73]$ ) has an effect on the light-induced transient of the $\mathrm{RC}$ absorption at $771 \mathrm{~nm}$ and on the electric conductivity of this material (Figure 7). Authors did not prove (and did not exclude) the possibility of direct electron transfer between the two materials. A possible explanation can also be the effect of the electric field perturbation induced by the charge reorganization due to the electron transfer within the protein on ITO.

When photosynthetic systems (light-harvesting antenna complexes or RCs) are bound to metal nanoparticles or to specific metal surfaces (like silver or gold), an additional effect is observed which offers exceptional, unique, and sophisticated application in nanoelectronics [74-77]. If proper geometric conditions are fulfilled, the electric field of 


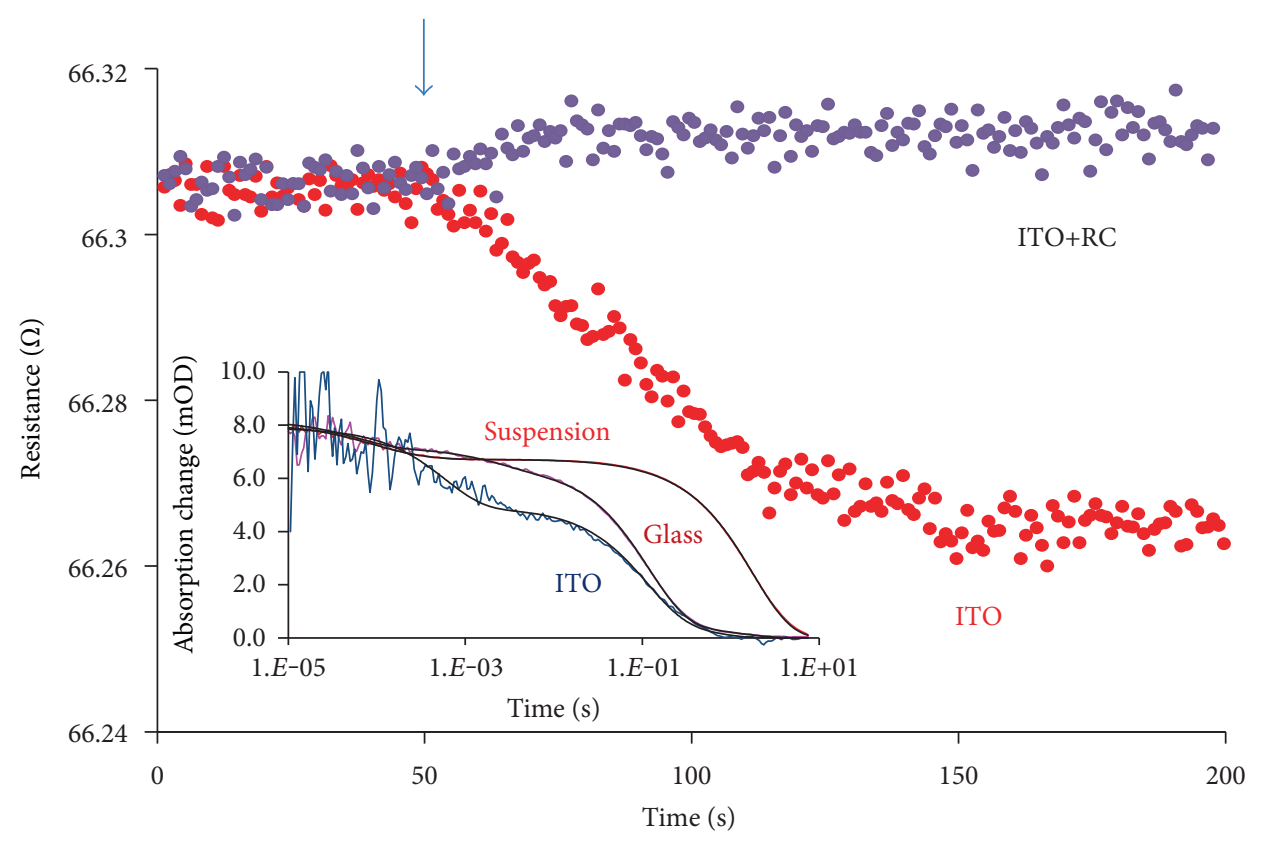

Figure 7: Light-induced conductivity changes of bare ITO and that decorated by RCs. Arrow indicates when light was switched on. Insert shows flash-induced absorption change at $771 \mathrm{~nm}$ (electrochromic shift of the BPheo absorption) recorded on detergent-solubilized RC deposited on the surface of borosilicate glass and ITO, as indicated. For explanation of different ranges of the transients, compare with Figure 6.

the optical dipole of the special pair can be in resonance interaction with the surface plasmons of the metal. The result of this plasmonic interaction is not only manifested in change of the absorption (parasitic absorption at the resonance frequencies) and of the fluorescence (enhancement) but also enhancing the performance of charge separation and all of the phenomena related to it.

\subsection{Redox Equivalents Are Created to Work. After excitation} by light, the RC transfers an electron to acceptor molecules ( $\mathrm{A}$ in Figure 4) and the oxidized primary donor is rereduced by a secondary donor molecule ( $D$ in Figure 4). The reduced acceptor $\left(\mathrm{A}^{-}\right)$then provides the driving force for further metabolic processes in living cells. The free energy of the excited charges can either be used to reducing external redox components in chemical reactions or wiring out in circuit elements of electrical networks. Different strategies with different biological components (from pigment molecules through membrane fragments or protein complexes to whole cells) and carrier matrices are applied in many laboratories, as already summarized in [78]. A short overview of using $\mathrm{RC}$ complexes is given here to demonstrate the possibility of harnessing the high quantum yield of charge separation.

For this purpose, PS II seems to be a reasonable choice. The utilization of the extreme capacity of this protein, which developed and maintains the oxygen-rich atmosphere of Earth, for at least partially satisfying the human energy requirements is not only a real challenge but also an up-todate task for the researchers. The structure and function of this protein are well characterized in many laboratories: it catalyzes water splitting and the evolution of molecular oxygen. There are already successful attempts to bind this complex to functional nanostructures and the capability for oxygen evolution, and stability were demonstrated [79]. It must be noted that besides the big challenge and the advantages, researchers are also facing disadvantages when using this protein. PS II is very sensitive to a complex autocatalytic photodegradation process. Every charge separation yields a certain probability of degradation which consumes inherently the active fraction of the protein after multiple turnovers [80].

Similar to PS II, PS I in plants and cyanobacteria also performs light-induced charge separation and is widely used when light-sensitive biohybrid systems are designed. For this purpose, PS I is a very promising material because of its relatively large structural stability and larger absorption cross section (compared to PS II core); also, it is easier to handle in laboratory investigations $[49,81]$. PS I can be attached to carrier surfaces either in dry monolayer form through specific chemical binding [49] or through self-assembled mono- or multilayer structures [50]. After the binding, the functional integrity, orientation, and the efficient electronic junction with the carrier matrices are secured. Approximately $+1 \mathrm{~V}$ photopotential and ca. $60 \%$ energy conversion efficiency make this biohybrid system promising for molecular electronic applications. Substantial increase in the photocurrent was demonstrated when multilayers of PS I are prepared on conducting substrate $[82,83]$.

Other promising materials are bacterial reaction centers purified from photosynthetic bacteria, which are widely used in many laboratories during the design of biohybrids for optoelectronic applications. Thanks to the Nobel prizes in 1988 (Michel, Huber, and Deisenhofer) and in 1992 (Marcus), researchers have a solid knowledge about its structure and function at atomic resolution. Although, being 
a membrane protein, RCs need detergent solubilization, it is not too difficult to handle it in laboratory environment. In addition, having relatively simple and well-known genome structure bacterial cultures is good materials for genetic modifications.

There are numerous demonstrations in the literature when purified bacterial reaction centers are bound to nanostructures. In these biohybrid systems, the proteins largely retained their photochemical activity and structural integrity and remained stable for weeks or months [84]. It is already well demonstrated that all types of reaction centers perform charge separation with a quantum yield close to unity. However, it drops (together with the energy yield) during the steps of the electron transfer and reduced to about $30 \%$ of the original one by the end of the chain. The main target of the researches is to find the most suitable species for RC purification. Specific mutations are designed for engineering longer lifetimes of the charge separated states and reducing the harmful environmental factors for possible (auto)degradation processes $[85,86]$.

2.4. Zero- (Quantum Dots), (Quasi) One-, Two-, and ThreeDimensional Carrier Matrices. Different biological materials, photosynthetic systems as well, have been bound successfully to various nanomaterials in the range from zero- to threedimensional (through (quasi) one- and two-dimensional) carrier matrices; so, functional hybrid materials can be created. The structural organizations (i.e., dimensional arrangements) of these materials are of special interest because they can be designed for special applications.

Since RC is the smallest pigment-protein complex that is capable of converting light energy to chemical potential, it is a big challenge to use it for this purpose in artificial systems; however, the purified protein has low absorption cross section. Note that the extinction coefficient is ca. $300 \mathrm{mM}^{-1} \mathrm{~cm}^{-1}$ at around $800 \mathrm{~nm}$ and ca. $30 \mathrm{mM}^{-1} \mathrm{~cm}^{-1}$ at around $860 \mathrm{~nm}$ [87]. In many laboratories, RCs are isolated together with their natural antenna complexes; however, it must be noted that this way of preparation increases the robustness of the pigment protein complex. Another direction is to keep the protein organization as simple as possible, and lightabsorbing components are attached by chemical engineering. One of the possible solutions is to increase the useful wavelength range by crosslinking fluorophore dye species, as artificial antenna, which has fluorescence overlapping the absorption of the RC in order to allow Förster type of excitation-energy transfer [88]. The other solution is to use quantum dots (QDs), which absorb ultraviolet and longwavelength light much more efficiently than natural lightharvesting proteins and transfer the excitation energy to photosynthetic RCs. Dry films of bacterial RCs and CdSe/ ZnS QDs, maintained at atmospheric humidity, are capable of maintaining their functional activity for at least some months according to measurements of their spectral characteristics, efficiency of energy transfer from QDs to RCs, and RC electron transport activity [89-91].

One-dimensional or "quasi" one-dimensional organizations, like nanotubes, nanowires, and nanofibers, offer other unique and sophisticated carrier matrices for functional assemblies. Although these systems are not easy to handle and require special laboratory conditions, recent developments in nanotechnology provide special tools and offer unique applications in nanoelectronics. Various biological systems, like enzymes, immune, and light sensitive proteins, are used to design biohybrid materials, e.g., for biosensor and optoelectronic applications. Several methods are worked out to bind RCs to carbon nanotubes, and their functionalities are investigated. It was found that the photochemical activity of the RC bound to carbon nanotubes or to nanowires is largely retained. The RCs create charge pairs after photoexcitation, and lifetimes of the charge recombination increased considerably, indicating the stabilization of the charges. When RCs are bound to carbon nanotube wires, there is a change in the conductivity, which accompanies the light activation. Authors conclude that CNT environment resembles the in vivo conditions for structural stability of the protein and provides a functional role interacting directly either with the electron/hole pair or through electromagnetic field interaction [84].

As mentioned above, using nanowires and bundles requires special lab conditions and expertise for sample preparation and application. Layer structures, sheets, and films are easier to handle either for preparation or measurements or for practical applications. In particular, when membrane proteins are layered on solid surface, an obvious choice is to use supporting layer membrane that mimics the in vivo (i.e., cell membrane) conditions. This arrangement can help an assembly (even "self-assembly") of the structure in monoor multilayers, keeps the integrity, and warrants proper orientation of the protein with respect to the surface and thus facilitates the (electronic) interaction between the components. This arrangement is typical when photosynthetic proteins are arranged in electrode surfaces for photovoltaic application. Thanks to the stabilization effects, the system works effectively and even photovoltage as high as $100 \mathrm{~V}$ [92] can be created.

In addition to SAMs, by using several physical and chemical binding procedures, which are adopted for specific or nonspecific binding of RCs to nanotubes [3], RCs are bound to different two-dimensional surfaces, like ITO [50], graphene [93], and CNT/conducting polymer [94] surfaces. The feasibility of using these systems for photoelectric energy conversion [50] and for detecting specific chemicals [50, 78], like herbicides, is demonstrated.

As it was mentioned above, two-dimensional systems are relatively easy to handle. The contact points for electric measurements can be done safely, the measurements can be arranged easily, and reasonable signals (magnitude and yield) are obtained [78, 95]. Furthermore, thanks to the recent advances in opto- and nanoelectronics, the theory and practical aspects of interactions between functionally active biological materials and carrier surfaces are more and more developed. Binding biological materials, for example, proteins, is not only a question of increasing the surface area and, consequently, increasing the numbers of bound molecules for a bigger signal. In more general, three-dimensional surfaces provide new quantum optical characteristics when interaction with light is considered. 


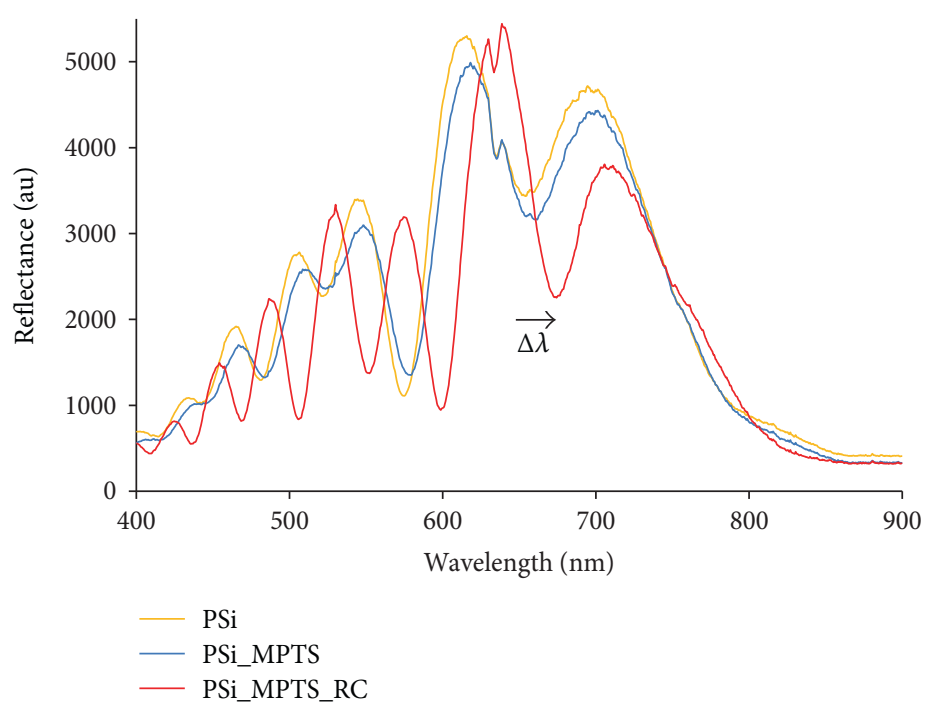

(a)

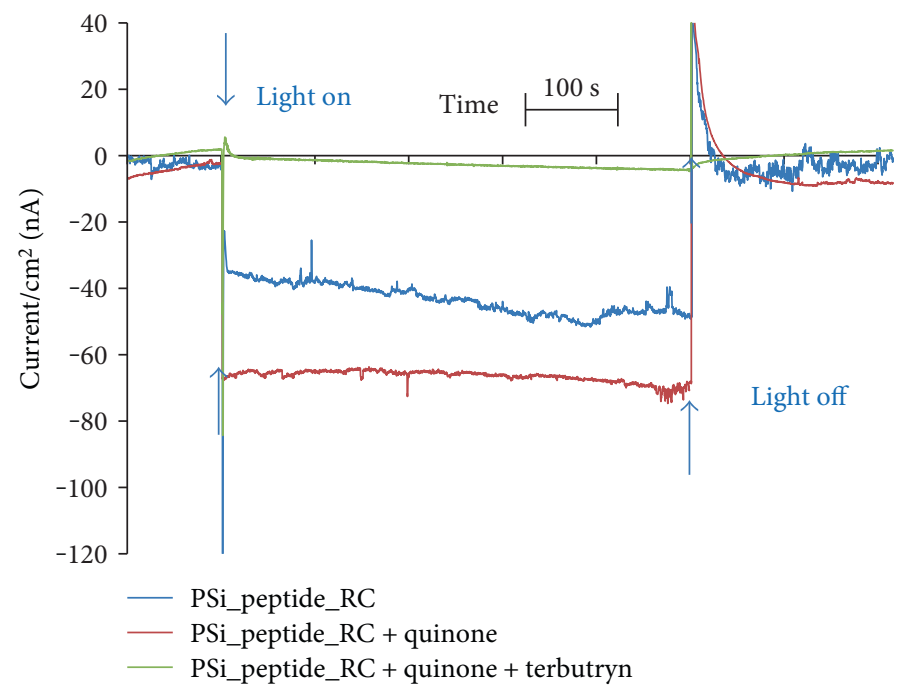

(b)

FIGURE 8: The reflection spectrum of the PSi before and after functionalization with RC (a) and light-induced photocurrent with the PSi/RC electrode in the presence of externally added UQ-0 mediator and the inhibitor terbutryn, as indicated. Traces correspond to the signal during consecutive illumination periods. Horizontal and vertical arrows, respectively, indicate the shifts in the specific reflection mode after the RC binding and the time when the illumination was switched on or off.

It is demonstrated nicely in the literature that porous silicon (PSi) multilayers can be predesigned to form Bragg mirror with characteristic reflection mode $[96,97]$. The photonic characteristics (the position and shape of the reflection mode in the spectrum) of the layer structure are determined by arrangement of the cavity layers and by the refractive index of the internal (intracavity) and external environment. When different substances are bound to porous silicon, RCs as well, the reflection mode is shifted in a concentrationdependent way. RC keeps its activity after binding to PSi, the donor and acceptor sides of the RC remain accessible for secondary donor and acceptor molecules [98, 99], and photocurrent is produced when inserted in a photoelectrochemical cell as a working electrode [4] (Figure 8).

The strong near-field interaction between plasmon polaritons in the surface of metal nanoparticles and biological materials is also demonstrated and proved to be extremely sensitive, for example, in biosensor applications, light harvesting, and/or photocurrent generation with PS 1 [74, 75]. Antenna-plasmon interaction enhanced fluorescence [76], and photocurrent generation using bacterial RC:LH1 complex assembled on nanostructured silver [77] was demonstrated (LH1, light-harvesting complex 1 of purple bacteria). Furthermore, surface plasmon resonance equipment was designed for successful detection of the herbicide atrazine, which is used in agriculture and blocks PS II electron transfer between $\mathrm{Q}_{\mathrm{A}}$ and $\mathrm{Q}_{\mathrm{B}}$ [65].

\section{Summary}

In summary, we conclude that investigation and development of biohybrid materials are important at different levels 
of the biological organization. The materials at the level of molecules are especially important because of understanding the phenomena undergoing on the boundary between the biological materials (macromolecules, membrane organizations, tissues, and so forth) and development of new types of materials for future applications (e.g., for biophotonics, photovoltaics, biosensors, and bioimaging). Light energyconverting systems, among them the RC proteins, are in focus of interest in many laboratories of research institutes and industries. These are nanosystems with global effects as concerns the evolution and maintenance of the atmosphere and the energetic basis of virtually all life on Earth. These molecular devices offer new solutions for future nanobionic technologies. Although the investigations are going on with huge efforts in large number of laboratories by using sophisticated and elegant methods, the real application is the task for future.

\section{Conflicts of Interest}

The authors declare that they have no conflicts of interest.

\section{Acknowledgments}

The research was supported by the European Union and the State of Hungary, cofinanced by the European Regional Development Fund in the project of GINOP-2.3.2.-152016-00009 'ICER,' from the New National Excellence Program of The Ministry of Human Capacities in Hungary (ÚNKP-16-3) and from the National Research, Development and Innovation (NKFI) Fund (OTKA PD116739 and OTKA K112688).

\section{References}

[1] R. E. Blankenship, Molecular Mechanisms of Photosynthesis, Wiley, Chichester, 2nd edition, 2014.

[2] L. Nagy, K. Hajdu, B. Fisher, K. Hernádi, K. Nagy, and J. Vincze, "Photosynthetic reaction centres-from basic research to application, possibilities," Notulae Scientia Biologica, vol. 2, pp. 7-13, 2010.

[3] L. Nagy, M. Magyar, T. Szabo et al., "Photosynthetic machineries in nano-systems," Current Protein \& Peptide Science, vol. 15, pp. 363-373, 2014.

[4] T. Szabó, M. Magyar, K. Hajdu et al., "Structural and functional hierarchy in photosynthetic energy conversion-from molecules to nanostructures," Nanoscale Research Letters, vol. 10, pp. 458-470, 2015.

[5] H. Tamiaki, K. Nishihara, and R. Shibata, "Synthesis of selfaggregative zinc chlorophylls possessing polymerizable esters as a stable model compound for main light-harvesting antennas of green photosynthetic bacteria," International Journal of Photoenergy, vol. 2006, Article ID 90989, 8 pages, 2006.

[6] S. Daliento, A. Chouder, P. Guerriero et al., "Monitoring, diagnosis, and power forecasting for photovoltaic fields: a review," International Journal of Photoenergy, vol. 2017, Article ID 1356851, 13 pages, 2017.

[7] M. R. Jones, "The petite purple photosynthetic powerpack," Biochemical Society Transactions, vol. 37, pp. 400-407, 2009.
[8] G. D. Scholes, G. R. Fleming, A. Olaya-Castro, and R. van Grondelle, "Lessons from nature about solar light harvesting," Nature Chemistry, vol. 3, pp. 763-774, 2011.

[9] R. J. Cogdell and J. G. Lindsay, "Can photosynthesis provide a 'biological blueprint' for the design of novel solar cells?," Trends in Biotechnology, vol. 16, pp. 521-527, 1998.

[10] R. J. Cogdell, A. T. Gardiner, P. I. Molina, and L. Cronin, "The use and misuse of photosynthesis in the quest for novel methods to harness solar energy to make fuel," Philosophical Transactions. Series A, Mathematical, Physical, and Engineering Sciences, vol. 371, no. 1996, article 20110603, 2013.

[11] O. Kruse, J. Rupprecht, J. H. Mussgnug, G. C. Dismukes, and B. Hankamer, "Photosynthesis: a blueprint for solar energy capture and biohydrogen production technologies," Photochemical \& Photobiological Sciences, vol. 4, pp. 957-970, 2005.

[12] J. W. Verhoeven and M. N. Paddon-Row, "Photoinduced charge separation and recombination under distance, orientation, and spin controlled conditions," International Journal of Photoenergy, vol. 3, no. 2, pp. 79-87, 2001.

[13] G. Luka, A. Ahmadi, H. Najjaran et al., "Microfluidics integrated biosensors: a leading technology towards lab-on-a-chip and sensing applications," Sensors, vol. 15, pp. 30011-30031, 2015.

[14] M. Magyar, K. Hajdu, T. Szabó et al., "Sensing hydrogen peroxide by carbon nanotube/horse radish peroxidase bio-nanocomposite," Physica Status Solidi B: Basic Solid State Physics, vol. 250, pp. 2559-2563, 2013.

[15] M. Magyar, L. Rinyu, R. Janovics et al., "Real-time sensing of hydrogen peroxide by ITO/MWCNT/horseradish peroxidase enzyme electrode," Journal of Nanomaterials, vol. 2016, Article ID 2437873, 11 pages, 2016.

[16] J. P. Giraldo, M. P. Landry, S. M. Faltermeier et al., "Plant nanobionics approach to augment photosynthesis and biochemical sensing," Nature Materials, vol. 13, pp. 400-408, 2014.

[17] O. Shoseyov and I. Levy, Nanobiotechnology: Bioinspired Devices and Materials of the Future, Humana Press Inc., Totowa, 2008.

[18] M. Darder, P. Aranda, and E. Ruiz-Hitzky, "Bionanocomposites: a new concept of ecological, bioinspired and functional hybrid materials," Advanced Materials, vol. 19, pp. 13091319, 2007.

[19] M. Dorogi, Z. Bálint, C. Mikó et al., "Stabilization effect of single-walled carbon nanotubes on the functioning of photosynthetic reaction centers," The Journal of Physical Chemistry $B$, vol. 110, pp. 21473-21479, 2006.

[20] L. Nagy, P. Maroti, and M. Terazima, "Spectrally silent light induced conformation change in photosynthetic reaction centers," FEBS Letters, vol. 582, pp. 3657-3662, 2008.

[21] G. Palazzo, A. Mallardi, F. Francia et al., "Spontaneous emulsification of detergent solubilized reaction center: protein conformational changes precede droplet growth," Physical Chemistry Chemical Physics, vol. 6, pp. 1439-1445, 2004.

[22] J. Fajer, "Chlorophyll chemistry before and after crystals of photosynthetic reaction centers," Photosynthesis Research, vol. 80, pp. 165-172, 2004.

[23] D. Karcz, B. Boroń, A. Matwijczuk et al., "Lessons from chlorophylls: modifications of porphyrinoids towards optimized solar energy conversion," Molecules, vol. 19, pp. 1593815954, 2014.

[24] C. A. Wraight and R. Clayton, "The absolute quantum efficiency of bacteriochlorophyll photooxidation in reaction 
centres of Rhodopseudomonas spheroides," Biochimica et Biophysica Acta (BBA) - Bioenergetics, vol. 333, pp. 246-260, 1974.

[25] R. van Grondelle, J. P. Dekker, T. Gillbro, and V. Sundstrom, "Energy transfer and trapping in photosynthesis," Biochimica et Biophysica Acta (BBA)-Bioenergetics, vol. 1187, pp. 1-65, 1994.

[26] A. Camara-Artigas and J. P. Allen, "Comparative analyses of three-dimensional models of bacterial reaction centers," Photosynthesis Research, vol. 3, pp. 227-237, 2004.

[27] J. Deisenhofer, O. Epp, K. Miki, R. Huber, and H. Michel, "Structure of the protein subunits in the photosynthetic reaction centre of Rhodopseudomonas viridis at $3 \AA$ resolution," Nature, vol. 318, pp. 618-624, 1985.

[28] G. Garab, "Self-assembly and structural-functional flexibility of oxygenic photosynthetic machineries: personal perspectives," Photosynthesis Research, vol. 127, pp. 131-150, 2016.

[29] C. R. D. Lancaster, M. V. Bibikova, P. Sabatino, D. Oesterhelt, and H. Michel, "Structural basis of the drastically increased initial electron transfer rate in the reaction center from a Rhodopseudomonas viridis mutant described at 2.00-A resolution," The Journal of Biological Chemistry, vol. 50, pp. 39364-39368, 2000.

[30] Y. Mazor, A. Borovikova, and N. Nelson, "The structure of plant photosystem I super-complex at 2.8 Å resolution," eLife, vol. 4, article e07433, 2015.

[31] P. Jordan, P. Fromme, H. T. Witt, O. Klukas, W. Saenger, and N. Krau, "Three-dimensional structure of cyanobacterial photosystem I at 2.5 A resolution," Nature, vol. 411, pp. 909-917, 2001.

[32] K. N. Ferreira, T. M. Iverson, K. Maghlaoui, J. Barber, and S. Iwata, "Architecture of the photosynthetic oxygen-evolving center," Science, vol. 303, pp. 1831-1838, 2004.

[33] M. Suga, F. Akita, K. Hirata et al., "Native structure of photosystem II at $1.95 \AA$ resolution viewed by femtosecond X-ray pulses," Nature, vol. 517, pp. 99-103, 2015.

[34] T. N. Tóth, N. Rai, K. Solymosi et al., "Fingerprinting the macro-organisation of pigment-protein complexes in plant thylakoid membranes in vivo by circular-dichroism spectroscopy," Biochimica et Biophysica Acta (BBA) - Bioenergetics, vol. 1857, pp. 1479-1489, 2016.

[35] J. Barber, "Towards a full understanding of water splitting in photosynthesis," International Journal of Photoenergy, vol. 6, no. 2, pp. 43-51, 2004.

[36] P. Mitchell, "Coupling of phosphorylation to electron and hydrogen transfer by a chemi-osmotic type of mechanism," Nature, vol. 191, pp. 144-148, 1961.

[37] R. E. Blankenship, T. M. Madigan, and C. E. Bauer, Anoxygenic Photosynthetic Bacteria, Kluwer Academic Publisher, Dordrecht, Boston, London, 1995.

[38] C. A. Wraight, "Proton and electron transfer in the acceptor quinone complex of photosynthetic reaction centers from Rhodobacter sphaeroides," Frontiers in Bioscience, vol. 9, pp. 309-337, 2004.

[39] J. P. Allen and J. C. Williams, "Photosynthetic reaction centers,” FEBS Letters, vol. 438, no. 1-2, pp. 5-9, 1998.

[40] M. L. Paddock, G. Feher, and M. Y. Okamura, "Proton transfer pathways and mechanism in bacterial reaction centers," FEBS Letters, vol. 555, pp. 45-50, 2003.

[41] L. Kalman and P. Maroti, "Stabilization of reduced primary quinone by proton uptake in reaction centers of Rhodobacter sphaeroides," Biochemistry, vol. 33, pp. 9237-9244, 1994.
[42] M. Y. Okamura, R. A. Isaacson, and G. Feher, "Primary acceptor in bacterial photosynthesis: obligatory role of ubiquinone in photoactive reaction centers of Rhodopseudomonas spheroides," Proceedings of the National Academy of Sciences of the United States of America, vol. 72, pp. 34913495, 1975.

[43] L. Nagy, F. Milano, M. Dorogi et al., "Protein/lipid interaction in bacterial photosynthetic reaction center: the role of phosphatidylcholine and phosphatidylglycerol in charge stabilization," Biochemistry, vol. 43, pp. 12913-12923, 2004.

[44] K. Hajdu, T. Szabó, M. Magyar et al., "Photosynthetic reaction center protein in nano structures," Physica Status Solidi B: Basic Solid State Physics, vol. 248, pp. 2700-2703, 2011.

[45] T. Szabó, G. Bencsik, M. Magyar et al., "Photosynthetic reaction centers/ITO hybrid nanostructure," Materials Science and Engineering C, vol. 33, pp. 769-773, 2013.

[46] V. Hartmann, T. Kothe, S. Poller et al., "Redox hydrogels with adjusted redox potential for improved efficiency in Z-scheme inspired biophotovoltaic cells," Physical Chemistry Chemical Physics, vol. 16, pp. 11936-11941, 2014.

[47] T. Szabó, E. Nyerki, T. Tóth et al., "Generating photocurrent by nanocomposites based on photosynthetic reaction centre protein," Physica Status Solidi B: Basic Solid State Physics, vol. 252, pp. 2614-2619, 2015.

[48] L. Zimányi and G. Garab, "Configuration of the electric field and distribution of ions in energy transducing biological membranes: model calculations in a vesicle containing discrete charges," Journal of Theoretical Biology, vol. 138, pp. 59-76, 1989.

[49] L. Frolov, Y. Rosenwaks, C. Carmeli, and I. Carmeli, "Fabrication of a photoelectronic device by direct chemical binding of the photosynthetic reaction center protein to metal surfaces," Advanced Materials, vol. 17, pp. 2434-2437, 2005.

[50] I. Carmeli, L. Frolov, C. Carmeli, and S. Richter, "Photovoltaic activity of photosystem I-based self-assembled monolayer," Journal of the American Chemical Society, vol. 129, pp. 12352-12353, 2007.

[51] W. Junge and H. T. Witt, "On the ion transport system of photosynthesis-investigations on a molecular level," Zeitschrift für Naturforschung, vol. 23b, pp. 244-254, 1968.

[52] H. T. Witt, "Coupling of quanta, electrons, fields, ions and phosphorylation in the functional membrane of photosynthesis. Results by pulse spectroscopic methods," Quarterly Reviews of Biophysics, vol. 4, pp. 365-477, 1971.

[53] H. Conjeaud, M. Michel-villaz, A. Vermeglio, and P. Mathis, "Location of field-sensitive carotenoid molecules in the chloroplast membrane. Arguments from low-temperature studies," FEBS Letters, vol. 71, pp. 138-141, 1976.

[54] D. M. Tiede, J. Vazquez, J. Cordova, and P. Marone, "Timeresolved electrochromism associated with the formation of quinone anions in the Rhodobacter sphaeroides R26 reaction center," Biochemistry, vol. 35, no. 33, pp. 10763 10775, 1996.

[55] D. M. Tiede, L. Utschig, D. K. Hanson, and D. M. Gallo, "Resolution of electron and proton transfer events in the electrochromism associated with quinone reduction in bacterial reaction centers," Photosynthesis Research, vol. 55, no. 2-3, pp. 267-273, 1998.

[56] R. J. Cogdell, S. Celis, H. Celis, and A. R. Crofts, "Reaction centre carotenoid band shifts," FEBS Letters, vol. 80, pp. 190194, 1977. 
[57] V. P. Shinkarev and C. A. Wraight, "Kinetic factors in the bicycle model of oxygen evolution by photosystem II," Photosynthesis Research, vol. 38, pp. 315-321, 1993.

[58] S. Osváth and P. Maróti, "Coupling of cytochrome and quinone turnovers in the photocycle of reaction centers from the photosynthetic bacterium Rhodobacter sphaeroides," Biophysical Journal, vol. 73, pp. 972-982, 1997.

[59] H. Zhang, A. Carey, K. Jeon et al., "A highly stable and scalable photosynthetic reaction center-graphene hybrid electrode system for biomimetic solar energy transduction," Journal of Materials Chemistry A, vol. 5, no. 13, pp. 6038-6041, 2017.

[60] S. C. Tan, L. I. Crouch, M. R. Jones, and M. Welland, "Generation of alternating current in response to discontinuous illumination by photoelectrochemical cells based on photosynthetic proteins," Angewandte Chemie, International Edition, vol. 51, pp. 6667-6671, 2012.

[61] T. Szabó, R. Csekő, K. Hajdu et al., "Sensing photosynthetic herbicides in an electrochemical flow cell," Photosynthesis Research, vol. 132, pp. 127-134, 2017.

[62] S. A. Trammell, L. Wang, J. M. Zullo, R. Shashidhar, and N. Lebedev, "Orientated binding of photosynthetic reaction centers on gold using Ni-NTA self-assembled monolayers," Biosensors \& Bioelectronics, vol. 19, no. 12, pp. 1649-1655, 2014.

[63] M. Chatzipetrou, F. Milano, L. Giotta et al., "Functionalization of gold screen printed electrodes with bacterial photosynthetic reaction centers by laser printing technology for mediatorless herbicide biosensing," Electrochemistry Communications, vol. 64, pp. 46-50, 2016.

[64] M. Giustini, M. Autullo, M. Mennuni, G. Palazzo, and A. Mallardi, "Polymer-photosynthetic protein multilayer architectures for herbicide optical detection," Sensors and Actuators B: Chemical, vol. 163, pp. 69-75, 2012.

[65] C. Nakamura, M. Hasegawa, N. Nakamura, and J. Miyake, "Rapid and specific detection of herbicides using a selfassembled photosynthetic reaction center from purple bacterium on an SPR chip," Biosensors \& Bioelectronics, vol. 18, pp. 599-603, 2003.

[66] D. J. K. Swainsbury, V. M. Friebe, R. N. Frese, and M. R. Jones, "Evaluation of a biohybrid photoelectrochemical cell employing the purple bacterial reaction centre as a biosensor for herbicides," Biosensors \& Bioelectronics, vol. 58, pp. 172-178, 2014.

[67] L. Fábián, E. K. Wolff, L. Oroszi, P. Ormos, and A. Dér, "Fast integrated optical switching by the protein bacteriorhodopsin," Applied Physics Letters, vol. 97, no. 2, article 023305, 2010.

[68] L. Fábián, Z. Heiner, M. Mero et al., "Protein-based ultrafast photonic switching," Optics Express, vol. 19, pp. 1886118870, 2011.

[69] H. Ohmori, L. Nagy, M. Dorogi, and M. Terazima, "Charge stabilization in reaction center protein investigated by optical heterodyne detected transient grating spectroscopy," European Biophysics Journal With Biophysics Letters, vol. 37, no. 7, pp. 1167-1174, 2008.

[70] M. Sakakura, S. Yamaguchi, N. Hirota, and M. Terazima, "Dynamics of structure and energy of horse carboxymyoglobin after photodissociation of carbon monoxide," Journal of the American Chemical Society, vol. 123, pp. 4286-4294, 2001.

[71] B. J. van Rotterdam, H. V. Westerhoff, R. W. Visschers et al., "Pumping capacity of bacterial reaction centers and backpressure regulation of energy transduction," European Journal of Biochemistry, vol. 268, no. 4, pp. 958-970, 2001.

[72] M. Lakatos, G. Groma, C. Ganea, J. K. Lanyi, and G. Varo, "Characterization of the azide-dependent bacteriorhodopsinlike photocycle of salinarum halorhodopsin," Biophysical Journal, vol. 82, no. 4, pp. 1687-1695, 2002.

[73] Y. Lu, Y. Xu, B. Liu, and J. Kong, "Photosynthetic reaction center functionalized nano-composite films: effective strategies for probing and exploiting the photo-induced electron transfer of photosensitive membrane protein," Biosensors \& Bioelectronics, vol. 22, no. 7, pp. 1173-1185, 2007.

[74] I. Kim, S. L. Bender, J. Hranisavljevic et al., "Metal nanoparticle plasmon-enhanced light-harvesting in a photosystem I thin film," Nano Letters, vol. 11, pp. 3091-3098, 2011.

[75] A. O. Govorov and I. Carmeli, "Hybrid structures composed of photosynthetic system and metal nanoparticles: plasmon enhancement effect," Nano Letters, vol. 7, pp. 620-625, 2007.

[76] E. Wientjes, J. Renger, A. G. Curto, R. Cogdell, and N. F. van Hulst, "Strong antenna-enhanced fluorescence of a single light-harvesting complex shows photon antibunching," Nature Communications, vol. 5, p. 4236, 2014.

[77] V. M. Friebe, J. D. Delgado, D. J. K. Swainsbury et al., "Bioelectronics: plasmon-enhanced photocurrent of photosynthetic pigment proteins on nanoporous silver," Advanced Functional Materials, vol. 26, pp. 285-292, 2016.

[78] L. Nagy, K. Hajdu, S. Torma et al., "Photosynthetic reaction center/carbon nanotube bundle composites," Physica Status Solidi B: Basic Solid State Physics, vol. 251, pp. 2366-2371, 2014.

[79] T. Noji, K. Kawakami, J. R. Shen et al., "Oxygen-evolving porous glass plates containing the photosynthetic photosystem II pigment-protein complex," Langmuir, vol. 32, pp. 7796$7805,2016$.

[80] J. Barber and B. Andersson, "Too much of a good thing: light can be bad for photosynthesis," Trends in Biochemical Sciences, vol. 17, no. 2, pp. 61-66, 1992.

[81] R. Das, P. J. Kiley, M. Segal et al., "Integration of photosynthetic protein molecular complexes in solid-state electronic devices," Nano Letters, vol. 4, pp. 1079-1083, 2004.

[82] P. N. Ciesielski, F. M. Hijazi, A. M. Scott et al., "Photosystem I - based biohybrid photoelectrochemical cells," Bioresource Technology, vol. 101, pp. 3047-3053, 2010.

[83] P. N. Ciesielski, C. J. Faulkner, M. T. Irwin et al., "Enhanced photocurrent production by photosystem I multilayer assemblies," Advanced Functional Materials, vol. 20, pp. 40484054, 2010.

[84] M. Magyar, K. Hajdu, T. Szabó et al., "Long term stabilization of reaction center protein photochemistry by carbon nanotubes," Physica Status Solidi B-Basic Solid State Physics, vol. 248, pp. 2454-2457, 2011.

[85] A. Kinka, K. Hajdu, M. Magyar et al., "Equilibrium concentration of singlet oxygen in photoreaction of reaction centre/carbon nanotube bio-nanocomposites," Physica Status Solidi B: Basic Solid State Physics, vol. 252, pp. 2479-2484, 2015.

[86] J. Tandori, É. Hideg, L. Nagy, P. Maróti, and I. Vass, "Photoinhibition of carotenoidless reaction centers from Rhodobacter sphaeroides by visible light. Effects on protein structure and electron transport," Photosynthesis Research, vol. 70, pp. 175-184, 2001.

[87] S. C. Straley, W. W. Parson, D. C. Mauzerall, and R. K. Clayton, "Pigment content and molar extinction coefficients of photochemical reaction centers from Rhodopseudomonas 
spheroides," Biochimica et Biophysica Acta, vol. 305, pp. 597-609, 1973.

[88] F. Milano, R. R. Tangorra, O. H. Omar et al., "Enhancing the light harvesting capability of a photosynthetic reaction center by a tailored molecular fluorophore," Angewandte Chemie (International Ed. in English), vol. 51, no. 44, pp. 1101911023, 2012.

[89] E. P. Lukashev, P. P. Knox, V. V. Gorokhov et al., "Purplebacterial photosynthetic reaction centers and quantum-dot hybrid-assemblies in lecithin liposomes and thin films," Journal of Photochemistry and Photobiology B, vol. 64, pp. 73-82, 2016.

[90] V. E. Zagidullin, E. P. Lukashev, P. P. Knox et al., "Properties of hybrid complexes composed of photosynthetic reaction centers from the purple bacterium Rhodobacter sphaeroides and quantum dots in lecithin liposomes," Biochemistry, vol. 79, pp. 1183-1191, 2014.

[91] I. Nabiev, A. Rakovich, A. Sukhanova et al., "Fluorescent quantum dots as artificial antennas for enhanced light harvesting and energy transfer to photosynthetic reaction centers," Angewandte Chemie International Edition, vol. 49, no. 40, pp. 7217-7221, 2010.

[92] H. Toporik, I. Carmeli, I. Volotsenko et al., "Large photovoltages generated by plant photosystem I crystals," Advanced Materials, vol. 24, no. 22, pp. 2988-2991, 2012.

[93] R. R. Tangorra, A. Antonucci, F. Milano et al., "Photoactive film by covalent immobilization of a bacterial photosynthetic protein on reduced graphene oxide surface," Materials Research Society Symposium Proceedings, vol. 1717, 2015.

[94] T. Szabó, M. Magyar, Z. Németh et al., "Charge stabilization by reaction center protein immobilized to carbon nanotubes functionalized by amine groups and poly(3-thiophene acetic acid) conducting polymer," Physica Status Solidi B: Basic Solid State Physics, vol. 12, pp. 2386-2389, 2012.

[95] W. Y. Zhou, W. J. Ma, Z. Q. Niu, L. Song, and S. S. Xie, "Freestanding single-walled carbon nanotube bundle networks: fabrication, properties and composites," Chinese Science Bulletin, vol. 57, pp. 205-224, 2012.

[96] V. Agarwal and J. A. del Río, “Tailoring the photonic band gap of a porous silicon dielectric mirror," Applied Physics Letters, vol. 82, pp. 1512-1514, 2003.

[97] J. O. Estevez, J. Arriaga, A. Méndez Blas, and V. Agarwal, "Enlargement of omnidirectional photonic bandgap in porous silicon dielectric mirrors with a Gaussian profile refractive index," Applied Physics Letters, vol. 94, article 061914, 2009.

[98] K. Hajdu, C. Gergely, M. Martin et al., "Porous silicon/photosynthetic reaction center hybrid nanostructure," Langmuir, vol. 28, pp. 11866-11873, 2012.

[99] K. Hajdu, C. Gergely, M. Martin et al., "Light-harvesting bio-nanomaterial using porous silicon and photosynthetic reaction center," Nanoscale Research Letters, vol. 7, pp. 400406, 2012. 

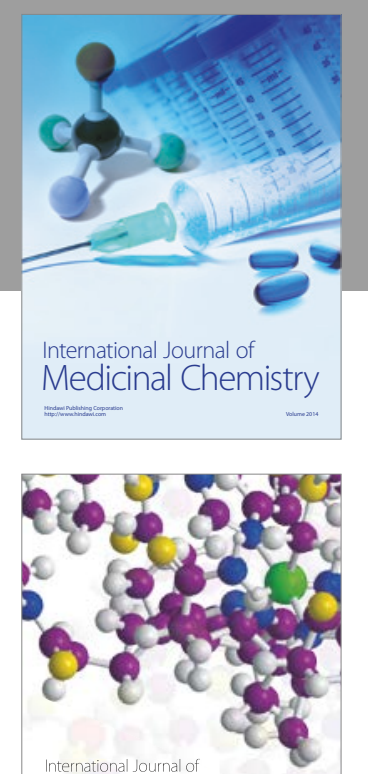

Carbohydrate Chemistry

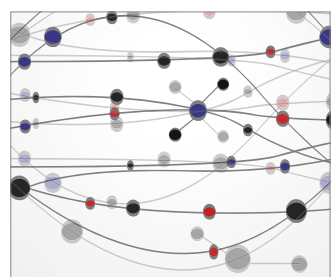

The Scientific World Journal
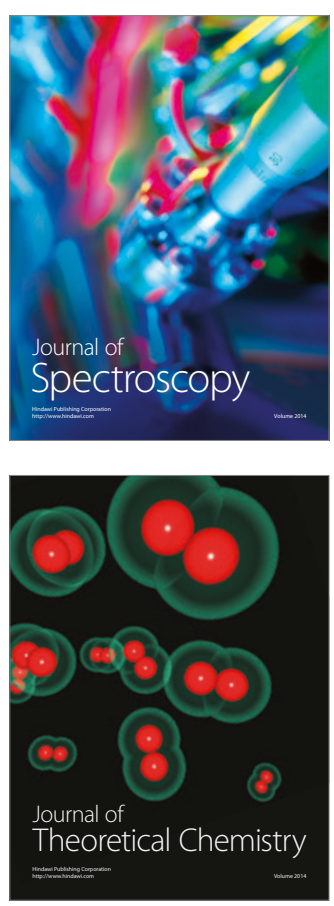
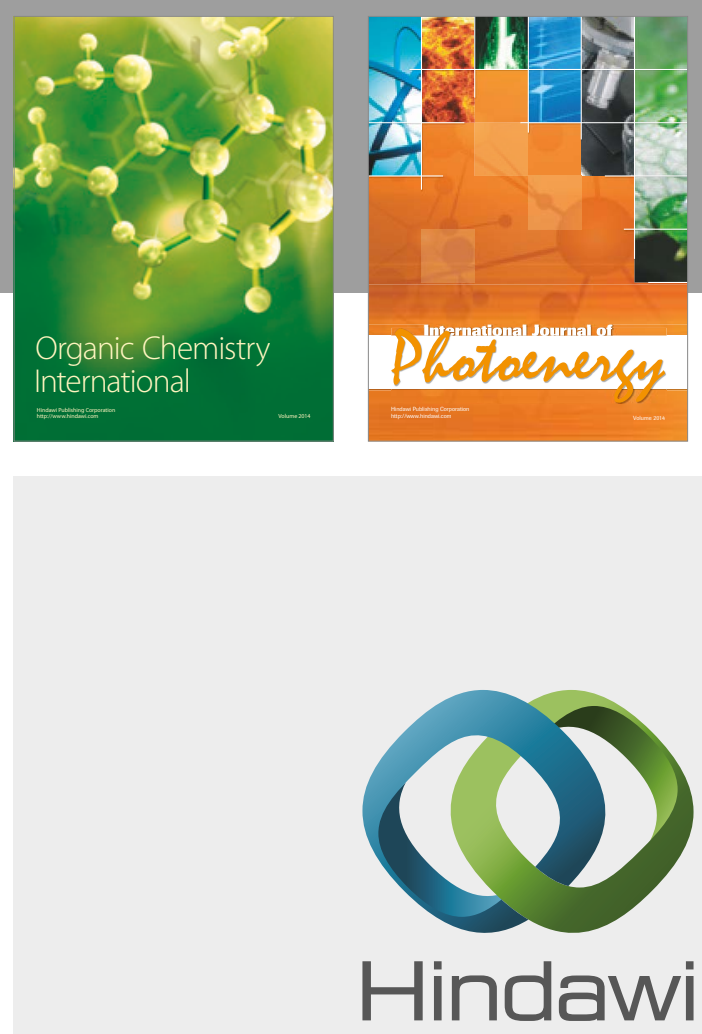

Submit your manuscripts at

https://www.hindawi.com

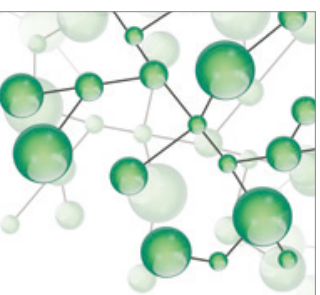

International Journal of

Inorganic Chemistry

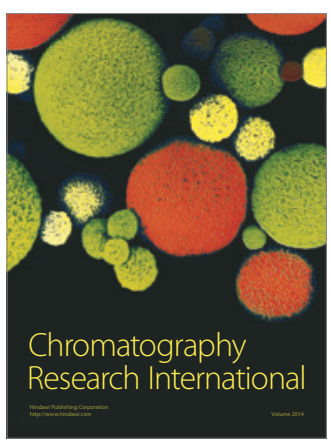

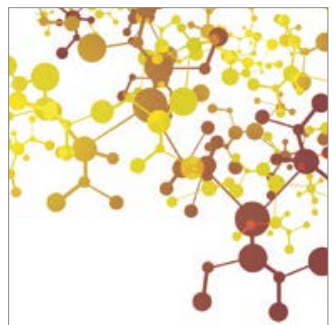

Applied Chemistry
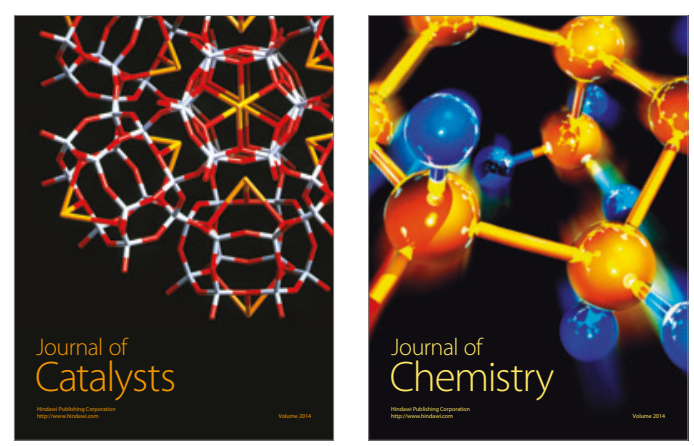
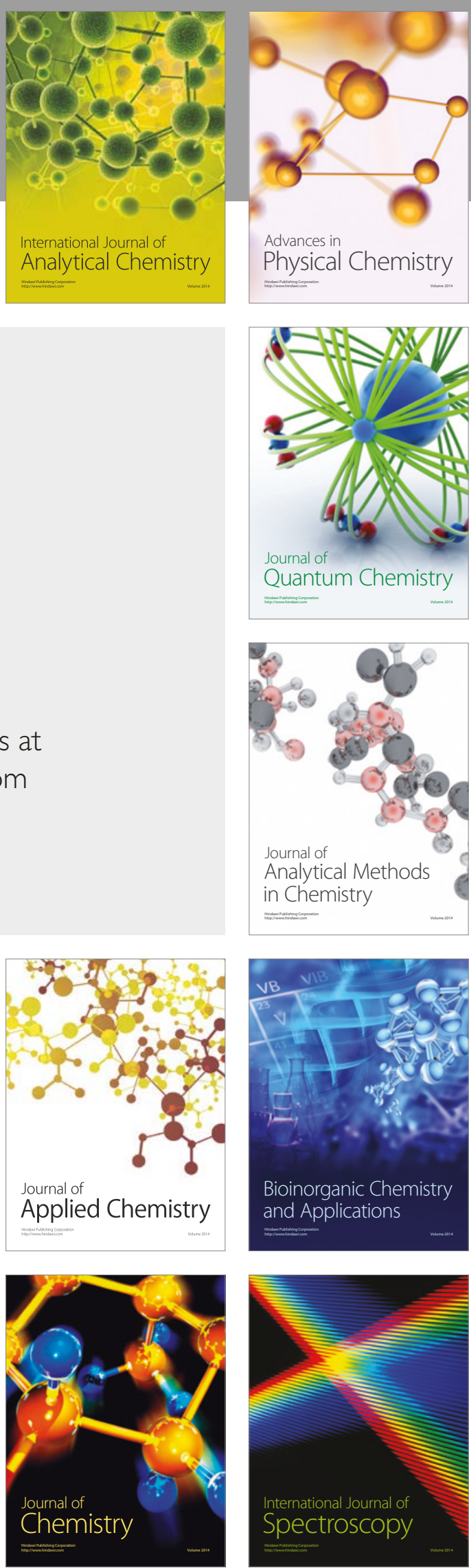